\title{
SEMIÓTICA DE CAPAS O EL SECRETO DESENCANTO DE LA BURGUESÍA ANÁLISIS DE LA CONVERSACIÓN, PROXÉMICA Y ELEMENTOS NO VERBALES COMO ELEMENTOS ESTRUCTURANTES DEL RELATO EN MODERATO CANTABILE, DE MARGARITA DURAS
}

BEATRIZ GIUDICI FERNÁNDEZ ${ }^{1}$

IES La Ería

\begin{abstract}
Resumen
A partir del análisis de la conversación, la proxémica y los elementos no verbales, este artículo pretende demostrar cómo Margarita Duras, autora de Moderato Cantabile, logra transformar la historia central en argumento, a partir de la superposición de capas narrativas, todas ellas caracterizadas por un mismo lugar y tiempo y dos actantes.

Palabras clave: Análisis de la conversación, proxémica, elementos no verbales, trama, argumento, capas.
\end{abstract}

\begin{abstract}
By means of the analysis of conversation, proxemics and non verbal elements, the aim of this article is to show how Margarita Duras, the author of Moderato Cantabile, manages to turn the central story into argument, by means of superimposing narrative layers, all of which share a place, a time and two actants. Key words: Conversation analysis, proxemics, non verbal elements, plot, argument, layers.
\end{abstract}

\section{INTRODUCCIÓN}

Muchas obras literarias suelen comenzar con la mención de acontecimientos nimios: el encuentro de dos amigos al cabo del tiempo (El gordo y el flaco, de Chéjov), una despedida (Las moscas de otoño, de Irene Nemirovsky) o un muchacho caminando por un parque (Sobre héroes y tumbas, de Ernesto Sábato). Otras, en cambio, se inician con la mención de algo que nos prepara para un final trágico (La gallina degollada, de Horacio Quiroga) o que nos induce a error (Bliss, de Katherine Mansfield). Las hay también que comienzan con una invitación (El Maestro y Margarita, de Mijail Bulgákov, inicia la segunda parte de la novela con un: “¡Sígueme, lector a mí, y sólo a mí, yo te mostraré ese amor!") o un ofrecimiento (Eugenio Oneguin, de Nikolai Gógol: "Recibe, amigo, la colección abigarrada de mis estrofas negligentes, que fruto son de [...] recuerdos que llenan el corazón de amargura"). Traspasamos esas primeras líneas

${ }^{1}$ IES La Ería (Asturias). Correo: giudici@telecable.es. Recibido: 07-01-2015. Aceptado: 06-05-2015. 
porque queremos saber, movidos por la curiosidad o encandilados por la historia que se ofrece a nuestra imaginación. En Moderato Cantabile, de Margarita Duras, la historia empieza un viernes en que Anne Desbaresdes ha llevado a su hijo a clase de piano con Mlle. Giraud. De repente, se oye un disparo y bajan a ver qué ha ocurrido. En el bar de abajo, ha tenido lugar un cirmen pasional -un hombre ha matado a una mujer de un balazo. Todo apunta a una típica historia policial: lugar, protagonistas, móvil. Pero nada más lejos de ello, como intentaremos demostrar.

Poco o nada sabemos de la mujer asesinada, a excepción de que es joven, está casada y es madre de tres hijos. También se nos dice que bebía mucho y que iba todas las tardes a un bar del otro lado del arsenal, donde se veía con un hombre en una sala recoleta del fondo. Menos aún sabemos de éste -sólo que es un obrero que trabaja en el arsenal. Desconocemos el nombre de ambos. Algo más conocemos de la otra pareja. Anne es una joven mujer rubia que está casada desde hace diez años con el director de una empresa de fundición, tiene un hijo y vive en una bonita casa con jardín situada al final del boulevard de la Mer, la zona acomodada de un pueblo marítimo, y bebe demasiado, mientras que Chauvin es un obrero que trabajaba en la fundición y que ahora pasa las horas muertas en un café de la zona fabril. Las similitudes, aunque escasas, llaman la atención: una mujer de clase acomodada inicia una relación con un hombre de nivel social inferior.

En lo que se refiere al desarrollo de la historia de Anne Desbaresdes y Chauvin en el tiempo lineal, ésta se podría reconstruir de la siguiente manera: Anne suele ver pasar por delante de su casa, a eso las 6 de la mañana, a los obreros que se dirigen a la zona fabril del pueblo. Se fija en uno de ellos, que la observa. En ocasión de la soirée que su marido organiza en su casa todos los años para el personal de la fábrica, se produce el encuentro con el obrero que la ronda y la observa: Chauvin. Ella, hastiada de una vida aparentemente vacía y de un matrimonio instalado en la rutina, busca una excusa para entrar en la zona "prohibida", la zona fabril: clases de piano para su hijo. Un viernes, que es el día en que lleva al niño a clases de piano con Mlle. Giraud, tiene lugar un asesinato pasional en el bar de abajo y Anne entra en el local con el pretexto de indagar. Allí está Chauvin, con quien empieza a verse, siempre con el pretexto de hablar sobre la mujer muerta. En una ocasión, Chauvin menciona la soirée y va desgranando detalles de su vida; ella, por su parte, admite saber quién es él. Se ven al día siguiente, sábado, y también el lunes y el martes, así como el viernes y el domingo siguientes. Durante este período el diálogo se desenvuelve en torno a la mujer asesinada y el porqué del asesinato, pero subyace otro más profundo -el verdadero diálogo- que en unas ocasiones parece indicar la relación con su marido:

Puis le temps est venu où quand il la regardait, parfois, il ne la voyait plus comme il l'avait jusque-là vue. Elle cessait d'être belle, laide, jeune, vieille, comparable à quiconque, même à elle-même. Il avait peur. C'était aux dernières vacances. L'hiver est venu².

\footnotetext{
${ }^{2}$ Luego llegó el momento en que, cuando él la miraba, a veces, ya no la veía como la había visto hasta entonces. Ella dejaba de ser hermosa, fea, joven, vieja, comparable a cualquiera, incluso a ella misma. Él tenía miedo. Fue durante las últimas vacaciones. Llegó el invierno. (Duras, M. (1999): Moderato Cantabile, Madrid, El Mundo, p. 72)
} 
y en otras un affair con Chauvin: "Si on ne buvait pas tant, ce ne serait pas possible?" le pregunta Chauvin. "Je crois que ce ne serait pas possible" ${ }^{4}$-le responde Anne (nótese la ambigüedad de "il", que podría referirse a uno y otro hombre, y la de "ce", que remitiría tanto a la relación con su marido como a la que ha entablado con Chauvin). Creemos que ambas historias confluyen en un idéntico final. La trasformación de la historia en argumento arrojará luz sobre la estructura profunda de la narración y justificará la hipótesis del trágico final de la historia de Mme. Desbaresdes y Chauvin, a semejanza del de la historia pasional que abre el relato.

La novela está estructurada en torno a ocho capítulos: el capítulo uno se desarrolla el viernes en el que se produce el asesinato; el dos, el sábado; el tres, el lunes; el cuatro, el martes; los capítulos cinco, seis y siete están concentrados en el segundo viernes; el ocho se dedica al domingo. Es decir que la acción se desarrolla a lo largo de diez días. Sin embargo, este tiempo de la realidad no es idéntico al tiempo de la narración, que suele estar acotado entre las cinco y seis de la tarde de determinados días -poco y nada se dice del tiempo comprendido entre el martes y el viernes-, aunque es posible que el martes hayan quedado en verse en el bar al día siguiente:

Anne: Je vais revenir ${ }^{5}$.

Chauvin: Demain'.

y en días sucesivos:

Chauvin: Il y a maintenant sept jours?

Anne: Sept nuits ${ }^{8}$.

Asimismo son ilustrativas estas palabras del narrador: [El domingo] "Anne Desbaresdes rejoinit Chauvin à la table où ils s'étaient assis les jours qui avaient précédé, au fond de la salle" ${ }^{\prime \prime}$. Este tiempo restringido de la narración finaliza al tocar la sirena de la fábrica a las seis, a excepción del segundo viernes, en el que Anne abandona el bar más tarde que de costumbre y llega a casa con notable retraso.

En síntesis, la historia que se nos cuenta es simple. La curiosidad lleva a Anne no sólo entrar en el bar situado debajo del piso de Mlle. Giraud, sino a volver al día siguiente y entablar conversación con un hombre que también ha presenciado el asesinato, para indagar qué puede haber motivado ese desenlace fatal. A partir de ahí sus visitas se repiten y alrededor de la conversación en torno al porqué del asesinato fluye la historia en torno a la cual se desenvuelve la narración. En el prólogo a la edición en castellano que hemos manejado (Véase bibliografía), Cristina Peri Rossi opina que

\footnotetext{
${ }^{3}$ Si no bebiéramos tanto, ¿no sería posible? (Duras, ibid, p. 71)

${ }^{4}$ Creo que no sería posible. (Duras, ibid, p. 71)

${ }^{5}$ Volveré. (Duras, ibid, p. 52)

${ }^{6}$ Mañana. (Duras, ibid, p. 52)

${ }^{7}$ Hace ahora siete días. (Duras, ibid, p. 66)

${ }^{8}$ Siete noches. (Duras, ibid, p. 66)

${ }^{9}$ Anne Desbaresdes se reunió con Chauvin en la mesa a la que se habían sentado, los días anteriores, en el fondo de la sala. (Duras, ibid, p. 86)
} 
Moderato Cantabile es el relato de una fascinación y que, como toda fascinación, se resiste al análisis racional, a la lógica. Para ella, Moderato Cantabile es la historia de una seducción y de una fascinación fatal, escrita con una gran economía y con una estructura que corresponde a la poesía. Sin embargo, un análisis detallado nos llevará a un nivel de interpretación más profundo que el de las meras coincidencias arriba mencionadas. Intentaremos probar que las dos historias, similares, que se narran constituyen un único argumento que se desarrolla en un tiempo muy acotado y en dos lugares principales y con dos actantes, representados -de entrada- por cuatro personajes. A tal fin, nos valdremos del análisis de la conversación, la proxémica y los elementos no verbales.

\section{ANÁLISIS DE LA CONVERSACIÓN}

Una de las posibilidades interesantes que plantea el análisis de la conversación es que nos permite acceder al significado de diálogos que pueden estar cohesionados o no estarlo y aun así ser coherentes, puesto que el lenguaje comunica más que información y pensamientos (Fasold 1984). De hecho, ofrece al hablante una gama de opciones que éste elige según las circunstancias. Es precisamente la combinación de estas dos propiedades del lenguaje -a saber, el comunicar más que información y pensamientos y el ofrecer un abanico de posibilidades de comunicación-, sumado al hecho de que ambas funciones se realicen de forma simultánea, lo que permite el estudio de la interrelación entre ambos y el de la competencia comunicativa que se trasluce en la conducta dialógica. Para ello hay que aproximarse al lenguaje desde una "matriz social", es decir, desde los grupos de hablantes y las funciones por ellos empleadas en contextos particulares, que devienen más importantes que la lengua como sistema lingüístico per se -aunque éste se halla presente en la base- o incluso los propios códigos individuales (Hymes 1974).

Si se aborda el estudio de la lengua no desde el propio código, sino desde el uso que el hablante hace de ella, lo primero que tendremos que definir será el contexto en que dicho uso tiene lugar, lo que nos conduce, a su vez, a la noción de comunidad lingüística, para pasar luego a analizar el hecho de habla y, por último, el acto de habla. Y al descubrir las reglas de uso lingüístico se podrá identificar la competencia comunicativa desplegada por los interlocutores.

Se entiende por comunidad lingüística aquella que comparte el conocimiento de las reglas de uso e interpretación del lenguaje (Hymes 1974:52). Dicho de otro modo, la comunidad de habla es el locus donde tiene lugar la interacción comunicativa y social y puede ser identificada a partir del análisis de un lenguaje compartido o de unas determinadas fronteras políticas o incluso desde la pertenencia a una clase social. De ello se desprende que lo primero que hay que determinar para proceder al análisis sociolingüístico de la conversación es determinar en qué comunidad social tiene lugar.

Por su parte, el hecho de habla es definido por autores como Duranti como el "mediador entre las locuciones de los individuos y los grupos sociales en los que participan" (Duranti 1988:220), es decir, como un puente entre un macro nivel y un 
micro nivel, ya que por una parte conserva información acerca del sistema social en su conjunto y por otra ofrece información acerca de actos individuales, mientras que para Saville-Troike se trata de un grupo unificado de componentes que comparten un mismo propósito comunicativo general y un mismo tema y en el que interactúan unos mismos participantes, los cuales mantienen la misma variedad lingüística, el mismo tono o clave y las mismas reglas de interacción, en un mismo escenario (Saville-Troike 1989:27). Sin embargo, conviene tener presente que sólo constituyen hechos de habla aquellas actividades gobernadas por reglas o normas para el uso lingüístico (Hymes ibid).

Se puede considerar al acto de habla como la unidad más pequeña -y problemática- de análisis, ya que, por una parte, es un fenómeno individual, es lo que la persona hace con el habla y a través del habla (Véase Austin) y tiene que ver con actividades gobernadas directamente por reglas o normas de uso lingüístico y, por otra, ejerce de mediador entre los distintos niveles gramaticales y el conjunto del hecho de habla o situación social, en tanto y en cuanto en él están presentes tanto la forma lingúística como las normas sociales (Hymes 1986:57). Puede tratarse de una sola locución o de varias y, al igual que un sustantivo puede constituir una frase nominal (por ejemplo, “¡Fuego!”), también él puede constituir al mismo tiempo un acto de habla y una situación de habla (por ejemplo, un rito que consiste en una única plegaria). Pero, por lo general, nos encontramos con una diferencia de magnitud: una fiesta (situación de habla), una conversación que tiene lugar en ella (hecho de habla) y una broma dentro de dicha conversación (acto de habla). Además, el mismo tipo de acto de habla puede estar presente en distintos tipos de hechos de habla, del mismo modo que un idéntico hecho de habla puede pertenecer a distintos contextos situacionales. Así, una broma (acto de habla) puede encontrarse en medio de una conversación privada, una disertación, una introducción formal, etc. (Hymes 1974:52).

Existen dos "modelos" de descripción sociolingüística que centran su descripción en la mencionada matriz social: el modelo del acto de habla (speech act) y el modelo de interacción. El primero no toma al código lingüístico (la lengua como sistema y como habla) de forma aislada, como marco limitado de referencia, sino que su contexto es la propia comunidad -entendida como un grupo interrelacionado de personas-, de manera tal que cualquier uso que se haga tanto del canal de comunicación como del código que éstas empleen forma parte de los recursos de los que disponen y se valen para comunicarse (Hymes 1984:4). Estas reglas operan a tres niveles, a saber, el social, el grupal y el individual, y la estructura del mensaje, aun conteniendo distintas funciones, depende de la función predominante (Jakobson). Así, para analizar un acto de habla hay que tener en cuenta las siguientes preguntas: 1) qué se dice, 2) de qué se está hablando (para ello es de suma importancia la elección del léxico -que no es baladí- y la estructura del discurso, entendido como el conjunto de elementos que conducen a la negociación del significado, vital para identificar el tema), 3) el espacio, es decir, dónde están los interlocutores, 4) cómo unos interlocutores se dirigen a los demás (i.e. el registro), y, por último, 5) quiénes son (por ejemplo, género, edad, clase social, etc.). Por el contrario, el segundo modelo, es decir, el interaccional, se centra no 
en el qué, sino en el cómo, por lo que es muy útil a la hora de estudiar aquellos casos que se apartan de la "norma".

Desde los postulados de la etnografía de la comunicación, se define a la cultura en términos de competencia comunicativa, es decir, como "lo que hay que saber para actuar de manera aceptable para los miembros de una comunidad y para hacerlo según un papel aceptable para todos" (Goodenough 1964:36). Saville-Troike ofrece una definición más prolija, ya que para ella:

la competencia comunicativa implica el conocimiento no sólo del código lingüístico, sino también de qué decir a quién y cómo hacerlo de forma adecuada según la situación, [y] tiene que ver con el conocimiento social y cultural que se presupone que los interlocutores poseen, lo cual les permite utilizar e interpretar la forma lingüística. [...] La competencia comunicativa se hace extensiva tanto al conocimiento como a las expectativas de quién puede hablar en determinadas circunstancias y quién no, cuándo hablar y cuándo permanecer callado, a quién dirigirse y cómo hacerlo a personas de diferente nivel social, así como a la identificación de la conducta no verbal adecuada según el contexto, [etc.] -en suma, todo lo que tiene que ver con la lengua y otros sistemas comunicativos en determinadas situaciones sociales. (Saville-Troike 1989: 21)

El análisis de la conversación es, de entrada, una técnica para el análisis del discurso, entendiéndose por tal aquellos elementos de índole socio-lingüística que permiten la negociación del significado, con lo que se podría decir que se trata de una herramienta para el análisis de un hecho de habla. Pero también puede abordarse desde postulados no "contaminados" por la sociolingüística y llevarse a cabo desde una perspectiva más "aséptica", es decir, descontextualizada. Sus unidades de análisis más simples son el turno de intervención y los pares adyacentes (por ejemplo, preguntarespuesta, saludo-saludo, ofrecimiento-aceptación/rechazo, etc.). Si bien es cierto que la conversación puede ser diseccionada sin tener en cuenta aspectos externos, no cabe duda de que toda conversación tiene lugar en la intersección de dos ejes: el socio-lingüístico y el cultural, y que la negociación del significado procede del (re) conocimiento y puesta en práctica de la competencia comunicativa por parte de los interlocutores.

Volviendo a lo que decíamos arriba, la vida cotidiana está repleta de ejemplos de dialógos no cohesionados pero coherentes. Si alguien pregunta: “¿Cómo tomas el café?" y la respuesta es: "Como siempre", el interlocutor sabrá que lo desea, por ejemplo, con leche y un terrón de azúcar, debido a un microcosmos de información compartida por ambos. La literatura utiliza este mismo recurso para negociar el significado. Veamos algunos ejemplos.

Al día siguiente del asesinato, Anne vuelve al bar, donde tiene lugar el siguiente diálogo:

Dueña: Il fait beau ${ }^{10}$.

Anne: J'avais soif ${ }^{11}$.

\footnotetext{
${ }^{10}$ Hace buen tiempo. (Duras, ibid, p. 22)

${ }^{11}$ Tenía sed. (Duras, ibid, p. 22)
} 
Lo normal habría sido asentir o hacer algún comentario sobre el tiempo: "Sí, por fin ha llegado el buen tiempo", "sí, pero hay mucha humedad", "sí, pero anuncian lluvias para mañana". El que la respuesta no tenga aparentemente nada que ver con el comentario de la dueña no implica que ésta no entienda el mensaje de Anne, que se está justificando por haber entrado -una mujer, y de su condición social- en ese bar y haber pedido un vaso de vino. Viendo el temblor de sus manos, la dueña comprende que la explicación vendrá en su momento, como ocurre unos segundos más tarde, cuando Anne dice que el día anterior a esa misma hora estaba en casa de Mlle. Giraud cuando oyó el disparo. Aparentemente, el motivo de la presencia de Anne en tal lugar es obtener información sobre el crimen.

Imaginémonos ahora el siguiente diálogo:

A: ¿Alguien quiere un café?

B: Sí, por favor. Sin azúcar.

y comparémoslo con este otro:

Chauvin: Vous permettez? ${ }^{12}$

Anne: C'est que je n'ai pas l'habitude, Monsieur ${ }^{13}$.

El mensaje no es que no está acostumbrada a beber, sino a aceptar invitaciones de extraños, con lo cual marca su territorio. Pocas líneas más adelante, cuando Chauvin le dice: «Vous vous promenez souvent dans la ville «14, contesta con idéntico fin: «Oui, tous les jours je promène mon enfant $\gg^{15}$ (no: Je me promène $\left.{ }^{16}\right)$. Una mujer no pasea sola, sino que lleva a su hijo de paseo. Chauvin recoge el mensaje y agrega: «Je vous disais qu'il avait longtemps que vous promeniez cet enfant au bord de la mer ou dans les squares ${ }^{17}$, con lo cual admite conocerla, al menos de vista.

Para alejar cualquier duda sobre su respetabilidad, Chauvin manifiesta lo siguiente:

Vous êtes Madame Desbaresdes. La femme du directeur d'Import Export et des Fonderies de la Côte. Vous habitez boulevard de la Mer ${ }^{18}$.

Pero Anne continúa con la misma táctica:

Anne: Il apprend le piano. Il a des dispositions, mais beaucoup de mauvaise volonté, il faut que j'en convienne. [...] Je voudrais pour cet enfant tant de choses ${ }^{19}$.

${ }^{12}$ ¿Me permite? (Duras, ibid, p. 23)

${ }^{13}$ Es que no estoy acostumbrada, ¿sabe? (Duras, ibid, p. 23)

${ }^{14}$ ¿Se pasea usted con frecuencia por la ciudad? (Duras, ibid, p. 25)

${ }^{15}$ Sí, todos los días paseo a mi hijo. (Duras, ibid, p. 26)

${ }^{16}$ Paseo.

${ }^{17}$ Le preguntaba si hacía mucho tiempo que paseaba a su hijo por la orilla del mar o por las plazas. (Duras, ibid, p. 27)

${ }^{18}$ Usted es la señora Desbaresdes. La esposa del director de Import Export y de las Fundiciones de la Costa. Usted vive en el Boulevard de la Mer. (Duras, ibid, p. 27)

${ }^{19}$ Estudia el piano [...] Tiene buena disposición, pero muy poca voluntad, tengo que reconocerlo [...] Quisiera para este niño tantas cosas. (Duras, ibid, p. 27) 
Chauvin: Je vous ai vue souvent. Je n'imaginais pas qu'un jour vous arriveriez jusqu'ici avec votre enfant $t^{20}$.

Anne: $\quad$ Si vous saviez tout le bonheur qu' on leur veut ${ }^{21}$.

Chauvin: Vous avez une belle maison au bout du boulevard de la Mer. Un grand jardin fermé22.

Anne: $\quad$ Mais ces leçons de piano, $\mathrm{j}^{\prime}$ en ai beaucoup de plaisir $^{23}$.

Una primera aproximación a este diálogo nos hablaría de la grosería de la protagonista, que una y otra vez incumple una norma básica de la socialización, cual es responder a los comentarios o preguntas del interlocutor. Es más, sus respuestas se centran en una tercera persona, aquello de lo que se habla, en este caso, su hijo. Es decir, quiere dejar claro que ha venido a hablar del crimen y no de su vida privada, en la que no desea ninguna ingerencia, y menos de un desconocido. La conversación vuelve al punto de partida: el crimen. Sorprende, sin embargo, que Anne le pregunte si trabaja en el pueblo. Él contesta que sí y agrega que si vuelve le comentará todo lo que haya averiguado al respecto. El diálogo se cierra con estas palabras:

Anne: $\quad$ Il m'aurait été impossible de ne pas revenir ${ }^{24}$.

Chauvin: Je suis revenu moi aussi pour la même raison que vous ${ }^{25}$.

Una mirada superficial a estas palabras nos diría que ambos han regresado al lugar del crimen por curiosidad. ¿Qué, si no, podrían significar las palabras "por la misma razón que usted"? Pero si nos adentramos más en las coordenadas que nos permiten descifrar los mensajes, veremos que son a veces muy sutiles y que sólo la pertenencia a una comunidad ofrece la clave para ello.

Hemos dicho que en un diálogo hay respuestas esperadas y respuestas socialmente aceptables. Sin embargo, hemos de agregar que los pares adyacentes no tienen por qué darse de forma pre-establecida. Claro está que hay innumerables situaciones en las que un comentario sí lleva aparejado el que se espera. Por ejemplo, a una pregunta suele seguirle una respuesta (Anne: «Je voudrais vous demandez, vous ne travaillez donc pas aujourd'hui? $»^{26}$. Chauvin: «Non, j'ai besoin de temps en ce moment $\gg^{27}$ ), sobre todo cuando uno de los interlocutores -por ejemplo, un médicotiene potestad para esperar que se le conteste abiertamente ("¿Cómo se siente hoy?" - "Estoy un poco mareada."). Pero hay también incontables ocasiones en las que la

\footnotetext{
${ }^{20}$ La he visto muchas veces. No podía imaginarme que un día usted llegaría hasta aquí con su hijo. (Duras, ibid, p. 27).

${ }^{21}$ Si supiera cuánta felicidad se les desea. (Duras, ibid, p. 28)

${ }^{22}$ Usted tiene una hermosa casa al final del Boulevard de la Mer. Un gran jardín cerrado. (Duras, ibid, p. 28)

${ }^{23}$ Pero para mí son una gran placer esas clases de piano. (Duras, ibid, p. 28)

${ }^{24}$ Me habría sido imposible no volver. (Duras, ibid, p. 29)

${ }^{25}$ Yo también volví por la misma razón que usted. (Duras, ibid, p. 29)

${ }^{26}$ Quería preguntarle, ¿usted no trabaja hoy? (Duras, ibid, p. 33)

${ }^{27} \mathrm{No}$, necesito tiempo en este momento. (Duras, ibid, p. 33 )
} 
respuesta aparece no inmediatamente, sino al cabo de una secuencia de turnos de intervención y no por ello hay interrupción alguna en el hilo conductor del diálogo.

Anne: Je suis revenue, voyez ${ }^{28}$.

Chauvin: Je voudrais que vous preniez un autre verre de $\operatorname{vin}^{29}$.

Chauvin: Il y a maintenant trois jours ${ }^{30}$.

Anne: $\quad$ C'est bon [le vin $]^{31}$.

$[\ldots]$

Anne: Je voudrais vous demandez, vous ne travaillez donc pas aujourd'hui? ? $^{32}$

Chauvin: Non, $\mathrm{j}^{\prime}$ ai besoin de temps en ce moment ${ }^{33}$.

Anne: Du temps pour ne rien faire! $!^{34}$

Chauvin: Rien, oui ${ }^{35}$.

Anne: La difficulté; c'est de trouver un prétexte, pour une femme, d'aller dans un café ${ }^{36}$.

Es decir, que el verdadero diálogo está compuesto por aquellas locuciones que ambos son capaces de rastear, descodificar y unir (en este caso, "Je suis revenue", "Il y a trois jours", "La difficulté; cést de trouver un prétexte, pour unne femme, d'aller dans un café") $)^{37}$, a pesar del «ruido" en el canal de la información (por ejemplo, "c'est bon le vin").

Para Goffman (1955:1967) las limitaciones de una locución y su respuesta no se hallan en las formalidades del lenguaje -ni siquiera en el sistema de turnos-, sino en las relaciones sociales, en cómo se presenta nuestra individualidad. Éste es el motivo por el cual, en vez de los "asépticos" turnos propios del análisis de la conversación, él prefiere hablar de turnos motivados ritualmente ( $y$, por ende, socialmente). Así, ha acuñado con gran fortuna el concepto de "footing" para referirse a aquellos procedimientos encaminados a presentar temas delicados de una forma aceptable desde el punto de vista social. Otra de las brillantes aportaciones de Goffman es considerar que la forma que el hablante elige para su expresión está guiada por el deseo de mantener su reputación ("face", es decir, prestigio, honor, dignidad, reputación) frente al interlocutor. Se trata, pues, de una máscara que cambia dependiendo de la audiencia y la situación social en la que se encuentre el individuo. Por lo general, todos intentamos mantener esta máscara

\footnotetext{
${ }^{28}$ He vuelto, ya lo ve. (Duras, ibid, p. 33)

${ }^{29}$ Quisiera que tomara otro vaso de vino. (Duras, ibid, p. 33)

${ }^{30}$ Hace ya tres días. (Duras, ibid, p. 33)

${ }^{31}$ Es bueno. (Duras, ibid, p. 33)

${ }^{32}$ Quería preguntarle, ¿usted no trabaja hoy? (Duras, ibid, p. 33)

${ }^{33}$ No, necesito tiempo en este momento. (Duras, ibid, p. 33 )

${ }^{34}$ ¿Tiempo para no hacer nada? (Duras, ibid, p. 33)

${ }^{35}$ Nada, sí. (Duras, ibid, p. 33)

${ }^{36}$ La dificultad, para una mujer, consiste en buscar un pretexto para ir a un café. (Duras, ibid, p. 34)

${ }^{37}$ He vuelto. Hace tres días. La dificultad, para una mujer, consiste en buscar un pretexto para ir a un café.
} 
-esta "persona", etimológicamente hablando- en nuestros encuentros sociales, hasta el punto de que su pérdida puede ocasionarnos un trastorno, un dolor, motivo por el cual intentamos cooperar con nuestros interlocutores a través del uso de estrategias de socialización y urbanidad ("politeness"). La conversación casi nunca es monolítica, puesto que a lo largo de la misma se asiste a una continua negociación del significado y de la reputación ("face"), guiada ésta por el deseo de mantener la que sea menos amenazadora -al menos, en situaciones "normales", puesto que en situaciones límite o en aquellas en las que hay un orden jerárquico muy marcado, el superior jerárquico puede, si la situación lo requiere, ejercer su papel sin sutilezas.

Goffman denominó "sintaxis de la acción" al estudio de la interacción cara a cara en ambientes naturales, es decir, no forzados (por ejemplo, teatrales, cinematográficos, etc.), cuyo objeto son los acontecimientos que tienen lugar durante una co-presencia y debido a la misma. Como sociólogo, estaba interesado en descubrir el orden social que prevalece dentro de las llamadas "unidades naturales de interación", así como las que se producen entre ellas (Goffman 1967:1-3). Desde el inicio de sus investigaciones, Goffman relacionó los modelos de habla y acción con el rito y la reputación ("face") y se resistió a la "secularización" de la sintaxis de la acción. Sin embargo, el estudio de estas dos cuestiones permite poner el énfasis en los individuos y su psicología, ya que se observa que la interacción está organizada, pero organizada para asegurar las necesidades rituales del individuo (Schegloff 1988:84-95).

Cuando Anne Desbaresdes vuelve al café el sábado, el local está casi desierto, a excepción de la dueña y Chauvin. Al verla la dueña le pregunta qué va a tomar y Anne pide un vino. Veamos el siguiente diálogo:

Anne: Vous vous étonnez peut-être de me revoir? ${ }^{38}$

Dueña: Dans mon métier, ... ${ }^{39}$

Anne: $\quad$ Come je vous disais, mon petit garçon prend les leçons de piano chez Mlle. Giraud. Vous deviez la connaitre ${ }^{40}$.

Dueña: Je la connais. Il y a plus d'un an que je vous vois passer, une fois par semaine, le vendredi, n'est-ce pas? ${ }^{41}$

Anne: Le vendredi, oui. Je voudrais un autre verre de $\operatorname{vin}^{42}[\ldots] C^{\prime}$ est un enfant qui est toujours seul. ${ }^{43}$

[Chauvin se le acerca]

Chauvin: Asseyez-vous ${ }^{44}$.

\footnotetext{
${ }^{38}$ ¿Acaso le extraña volver a verme? (Duras, ibid, p. 32)

${ }^{39}$ En mi oficio ... (Duras, ibid, p. 32)

${ }^{40}$ Como le decía, mi hijo tiene clases de piano en casa de la señorita Giraud. La conocerá usted, supongo. (Duras, ibid, p. 32)

${ }^{41}$ La conozco. Hace ya más de un año que la veo pasar, una vez por semana, el viernes, ¿no es así? (Duras, ibid, p. 32)

${ }^{42}$ El viernes, sí. Quisiera otro vaso de vino. (Duras, ibid, p. 32)

${ }^{43}$ Es un niño que siempre está solo. (Duras, ibid, p. 32)

${ }^{44}$ Siéntese. (Duras, ibid, p. 32)
} 
Este corto diálogo, que antecede al anterior que hemos analizado, es interesante porque, aunque aparentemente se establece entre Anne y la dueña, el verdadero destinatario del mensaje es Chauvin, pues es a él a quien le dice que quizá esté sorprendido de que haya vuelto y al que confiesa que lo ha hecho porque está sola. Es decir, admite su propia soledad, no la del niño. Se trata, en realidad, de un diálogo a tres bandas, en el que la dueña ejerce de excusa mediadora. Por ejemplo, cuando Anne le dice que debe de conocer a la profesora de piano, puesto que vive arriba, la dueña le responde: "la conozco" y agrega: "Hace más de un año que la veo pasar, una vez por semana, el viernes". Aunque parezca una obviedad, la referencia al "la" de "la conozco" no es la misma que la del "la" de "la veo pasar", puesto que en el primer caso se trata de Mlle. Giraud, mientras que en el segundo es la propia Anne. Y la prueba de que el mensaje no va dirigido a la dueña es la respuesta que provoca: Chauvin se le acerca y la invita a sentarse a una mesa mediante el empleo del imperativo -"Asseyez-vous"-, con el que también marca su territorio y la relación de dominio.

En lingüística, se suele definir al "yo" gramatical como la persona que habla, el "tú/usted" como aquella a quien se habla y el "él/ella" como aquello de lo que se habla, es decir la no-persona. Es traquilizador estar al abrigo de las etiquetas, pero no siempre la realidad es así de simple. El diálogo que acabamos de ver se da entre dos interlocutores, pero creemos que el "vous" es Chauvin debido justamente a las consecuencias perlocutorias que las palabras de Anne traen aparejado. Podría objetarse que hay dos consecuencias perlocutorias: la retirada de la dueña de la escena y la llegada de Chauvin. Como mucho la actitud de la dueña podría estar determinada por el valor ilocutorio de las palabras de Anne, pero quien recibe el mensaje, a quien va dirigido el mensaje y actúa en consecuencia es Chauvin, el verdadero "tú" del diálogo.

A continuación se sientan a una mesa apartada, frente a frente, y ella confiesa: "Je suis revenue, voyez" 45 , a lo que Chauvin contesta: "Il y a maintenant trois jours" 46. Ha tenido lugar un encuentro fortuito entre una mujer sola y un hombre que admite conocerla; ella ha vuelto y él la esperaba; se han cruzado dos destinos. Anne alaba el vino, le pregunta si ese día no trabaja, le habla de la dificultad de una mujer de encontrar un pretexto para ir a un café, retoman la conversación sobre la mujer asesinada, sobre sus gritos. Chauvin explica:

Ils s'étaient connus par hasard dans un café, peut-être même dans ce café-ci qu'ils fréquentaient tous les deux. Et ils ont commencé à se parler de choses et d'autres ${ }^{47}$.

Salta a la vista la similitud del encuentro entre las dos parejas. Al día siguiente vuelven a verse y Chauvin confiesa haberla visto observar, de madrugada, desde el ventanal a los obreros que se dirigen al arsenal ("Souvent vous regardez ces hommes

\footnotetext{
${ }^{45}$ He vuelto, ya lo ve. (Duras, ibid, p. 33)

${ }^{46}$ Hace ya tres días. (Duras, ibid, p. 33)

${ }^{47}$ Se habían conocido por casualidad en un café, quizás incluso en este café que los dos frecuentaban. Y empezaron a hablarse de una cosa y otra. (Duras, ibid, p. 34)
} 
qui vont à l'arsenal, surtout l'été, et la nuit, lorsque vous dormez mal"48). Anne rebaja la distancia social y personal al matizar inequívocamente el comentario diciendo: "le souvenir de certains d'entre eux, la nuit m'est revenu" ${ }^{49}$. Aquí el uso del plural ("certains d'entre eux" ${ }^{50}$ ) evita reducir su nivel de "face" hasta unos límites peligrosos desde el punto de vista del decoro.

Al cabo de una semana -el siguiente viernes, para ser más exactos- la barrera protectora de la reputación se ha ido debilitando, hasta el punto de encontrarse bajo mínimos y sólo perdura el uso del "vous". Los personajes se hallan en un plano de igualdad social y, sobre todo, personal. Chauvin ha logrado invadir el territorio de Anne, bien sea mediante el uso del imperativo ("Asseyez vous", "Parle moi" 51), bien a través del lenguaje soez ("Chauvin proféra un mot à voix basse. Le regard

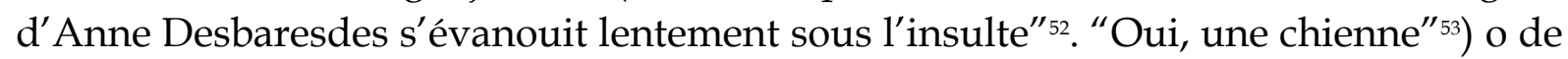
comentarios inapropiados hacia una mujer, sobre todo si está casada y es casi una extraña:

Vous étiez accoudée à ce grand piano. Entre vos seins nus sous votre robe, il y a cette fleur de magnolia [...] Quand vous vous penchez, cette fleur frôle le contour extérieur de vos seins. Vous l'avez négligemment épinglée, trop haut. C'est une fleur énorme, vous l'avez choisie au hasard, trop grande pour vous. Ses pétales sont encore durs, elle a justement atteint la nuit dernière sa pleine floraison ${ }^{54}$.

Hasta el momento se ha visto que una coincidencia entre las dos parejas es su encuentro casual en un café y otra, que ambas empiezan a hablar -la primera, de esto y de lo otro y la segunda, de un crimen. La tercera coincidencia gira en torno a los personajes: la mujer asesinada es también una mujer joven, casada (aunque con tres hijos), que bebe más de la cuenta (de hecho, solía ser vista en los bares de la zona del arsenal completamente ebria), y el hombre, un obrero de una de las fábricas de la ciudad.

\section{PROXÉMICA Y ELEMENTOS NO VERBALES}

En el relato, el espacio puede estudiarse desde un plano horizontal, como el locus en el que se desarrolla la acción, pero también desde la importancia discursiva que adquiere en él la distancia interpersonal. Esta distancia está determinada social y

\footnotetext{
${ }^{48}$ Usted mira con frecuencia a esos hombres que van al arsenal, sobre todo en verano y, por la noche, cuando duerme mal. (Duras, ibid, p. 40)

${ }^{49}$... vuelve a usted su recuerdo. (Duras, ibid, p. 40)

${ }^{50}$ Alguno de ellos. (Duras, ibid, p.

${ }^{51}$ Siéntese. Hábleme. (Duras, ibid, p. 32; p. 34)

${ }^{52}$ Chauvin profirió una palabra en voz baja. La mirada de Anne Desbaresdes desfalleció lentamente ante el insulto. (Duras, ibid, p. 68)

${ }^{53}$ Sí, una zorra. (Duras, ibid, p. 73)

${ }^{54}$ Usted estaba apoyada en ese gran piano. Entre sus pechos desnudos debajo del vestido, hay una flor de magnolia [...] Cuando usted se inclina, esa flor roza el contorno exterior de sus pechos. Usted la ha sujetado con descuido, demasiado arriba. Es una flor enorme, la ha elegido al azar demasiado grande para usted. Sus pétalos están todavía tersos, alcanzó precisamente anoche su completa eflorescencia. (Duras, ibid, p. 67)
} 
culturalmente y su análisis permite acceder al significado profundo de las relaciones que se establecen entre los personajes. Intentaremos demostrar que la distancia entre Anne Desbaresdes y Chauvin se desplaza hacia lo que Edward Hall denominó “distancia íntima", clave para comprender la relación entre ambos. El primer contacto se hace desde una distancia pública. De hecho, Chauvin alude a la recepción que todos los años se organiza en casa de M. Desbaresdes para el personal de las compañías siderúrgicas: "Vous aviez une robe noire très décolletée. Vous nous regardiez avec amabilité et indifférence" 55 -confiesa. Es posible que Chauvin no haya pasado inadvertido para Anne, quien sin duda también se acuerda de él, ya que cuando él se presenta (“Je m” appelle Chauvin"56) ella le contesta que lo sabía ("Je le savais" ${ }^{57}$ ). También admite haber rondado su casa y haberla observado en silencio desde el exterior ("On voyait bien vôtre jardin, comme il est entretenu, lisse comme un miroir. C'était tard. Le grand couloir du première étage était encore allumé" ${ }^{58}$ ).

Cuando hablan por primera vez en el bar el viernes, ambos mantienen una distancia social, que es la propia entre extraños (quizá la misma que mantuvieron en la recepción). A medida que las citas se hacen más frecuentes y públicas, la distancia social tiene que haberse acortado, lo que ha dado pie a comentarios sobre su relación. Ya el sábado, "la patronne les lorgnait, intriguée de les voir tant s'attarder, sans doute" ${ }^{59} \mathrm{y}$ el lunes, “le premiers hommes entrèrent au café, s'étonnèrent, interrogèrent la patronne du regard. Celle-ci, d'un léger mouvement d'épaules, signifia qu'elle même n'y comprenait pas grand-chose" 60 . Al día siguiente, Chauvin comenta: "On va le savoir, dans la ville, tous se sait de la même façon" y ella le responde: "Que je bois en votre compagnie" ${ }^{61}$. Tres días más tarde, "des hommes au bar regardèrent encore cette femme, s'étonnèrent encore, mais de loin"62. Y el domingo, "un groupe d'ouvrières entra, qui les avaient déjà vu [...] Ils évitèrent de les regarder, étant au courant, eux aussi, comme la patronne et toute la ville" ${ }^{63}$. "Les hommes évitèrent encore de porter leurs yeux sur cette femme adultère" ${ }^{\prime 64}$.

\footnotetext{
${ }^{55}$ Usted llevaba un traje negro muy escotado. Nos miraba con amabilidad e indiferencia. (Duras, ibid, p. 38)

${ }^{56}$ Me llamo Chauvin. (Duras, ibid, p. 48)

${ }^{57}$ Lo sabía. (Duras, ibid, p. 48)

${ }^{58}$ Se veía bien su jardín. Qué bien cuidado está, parece un espejo. Era tarde. Había luz en el pasillo de la primera planta. (Duras, ibid, p. 44)

${ }^{59}$ La dueña los miraba de reojo, intrigada sin duda de verles demorarse tanto. (Duras, ibid, p. 29)

${ }^{60}$ Los primeros hombres entraron en el café, se sorprendieron, interrogaron a la dueña con la mirada. Ésta, con un ligero movimiento de hombros, expresó que ella misma no entendía muy bien de qué iba. (Duras, ibid, p. 39)

${ }^{61}$ La gente lo sabrá en la ciudad, todo acaba sabiéndose de la misma manera [...] El que beba vino en su compañía. (Duras, ibid, p. 44)

${ }^{62}$ Algunos hombres de la barra miraron una vez más a aquella mujer, seguían sorprendidos, pero de lejos. (Duras, ibid, p. 66)

${ }^{63}$ Entró un grupo de obreros, quienes ya les habían visto. Evitaron mirarles, al corriente como estaban ellos también, al igual que la dueña y toda la ciudad. (Duras, ibid, p. 92)

${ }^{64}$ Los hombres evitaron una vez más posar la mirada sobre aquella mujer adúltera. (Duras, ibid, p. 92)
} 
En sucesivos encuentros la distancia entre ambos se acorta aún más, puesto que podrían tocarse si extendieran el brazo. Al día siguiente del asesinato, cuando Anne vuelve al bar y empieza a hablar con Chauvin, aparentemente un desconocido, él la mira fijamente a los ojos. Es más, cuando el bar empieza a llenarse de obreros, Chauvin les hace sitio en la barra, para lo cual se acerca más a ella. Sin embargo, las convenciones sociales establecen un límite a esta distancia (no olvidemos que Anne pertenece a un clase social superior y es una mujer casada). Pero ambos rompen las reglas al empezar a encontrarse de forma más o menos asidua en el bar, a sentarse a la misma mesa, a hablar. Así, a medida que Anne vuelve con la excusa de indagar sobre el crimen la distancia entre ellos se estrecha y deviene personal: "Je n'imaginais pas qu'un jour vous arriveriez jusqu'ici avec votre enfant" ${ }^{\prime 65}$, le confiesa Chauvin, separado de ella por unos pocos centímetros. En otras ocasiones es la propia Anne la que se inclina hacia él, que la mira mientras bebe, como ocurre el lunes cuando ella vuelve al bar y él la invita a sentarse a una mesa. En esta ocasión Chauvin hace uso del imperativo, posiblemente el registro al que está acostumbrado, aunque todavía mantiene el "vous".

El lunes Anne vuelve al bar y habla con la dueña, al otro lado del mostrador. Se ha visto cómo el verdadero destinatario del mensaje es el propio Chauvin, quien, dándose por aludido, se aproxima y la invita a sentarse a una mesa. Entonces, Chauvin, dirigiendo su mirada a la puerta del establecimiento, la invita a otro vaso de vino, el tercero, para ser más exactos, y dice, desplazando su mirada hacia ella: "Il y a maintenant trois jours" ${ }^{66}$. Este comentario es ambiguo, ya que un primer nivel de interpretación llevaría a pensar que se refiere a los tres días que han pasado desde el trágico incidente, pero es precisamente el hecho de que él vuelva la mirada hacia ella lo que induce a pensar que se trata de otro mensaje: hace tres días que no se han visto. "Je suis revenue, voyez" ${ }^{67}$-había admitido Anne, como por azar, justo antes de aceptar su invitación. Aparentemente el regreso de Anne puede tener que ver con sus dudas respecto al porqué del asesinato de la mujer y a la promesa de Chauvin de estar pendiente de noticias al respecto: "Si vous revenez, j'essaierais de savoir autre chose et je vous le dirais" ${ }^{68}$. Pero el motivo es otro y la distancia física, más corta.

Si el viernes la distancia entre ambos es social, el lunes es de otra índole, puesto que no sólo están sentados juntos a una mesa, sino que sus manos están juntas. “El releva la main, la laissa retomber près de la sienne sur la table, il la laissa là. Elle remarqua ces deux mains posées côté à côté pour la première fois" ${ }^{69}$. Al día siguiente la distancia se ha acortado, como se desprende de lo siguiente: "Il s'approcha de son

\footnotetext{
${ }^{65}$ No podía imaginarme que un día usted llegaría hasta aquí con su hijo. (Duras, ibid, p. 27)

${ }^{66}$ Hace ya tres días. (Duras, ibid, p. 33)

${ }^{67}$ He vuelto, ya lo ve. (Duras, ibid, p. 33)

${ }^{68}$ Si vuelve, procuraré saber algo más y se lo diré. (Duras, ibid, p. 28)

${ }^{69}$ Él levantó la mano, la dejó caer cerca de la de ella encima de la mesa y la dejó allí. Ella reparó en esas dos manos, una al lado de la otra por primera vez. (Duras, ibid, p. 38)
} 
visage assez près, posa ses mains contre les siennes sur la table" 70 , al tiempo que ella no deja de mirarle la boca. En esta distancia corta la comunicación es no sólo verbal, sino que se da a través de otros códigos, tales como la mirada y el tacto.

El viernes siguiente Anne vuelve a llevar a su hijo a clase de piano y mientras el niño juega fuera Chauvin la invita a entrar en el café. Primero toman algo en un extremo del mostrador y luego se dirigen al fondo de la sala y se sientan a una mesa. La conversación deviene íntima, plagada de doble sentido (hace ya siete días que se ven). De repente se lee: “Les mains de Chauvin s'approchèrent de celles d'Anne Desbaresdes. Elles furent toutes quatre sur la table, allongées"71. Esta superposición de códigos -el verbal y los no verbales- refuerzan la idea de que existe una relación entre ambos. En la última cita en el bar, Anne llora. Chauvin la mira a los ojos y comprende: ha venido sola y ha venido a despedirse. En esta ocasión se lee: “Il posa sa main à côté de la sienne, sur la table, dans l'écran d'ombre que faisait son corps" ${ }^{72}$. Las manos de ambos sobre la mesa, frías y tremblorosas, en pose mortuoria ("Leurs mains restèrent ainsi, figées dans leur pose mortuaire" 73) al igual que sus labios ("Leur lèvres restèrent l'une sur l'autre, posées, afin que ce fût fait et suivant le même rite mortuaire que leurs mains, un instant avant, froides et tremblantes" ${ }^{\prime 74}$-indicios estos del trágico final de su affair.

\section{ESPACIO NARRATIVO Y ELEMENTOS EXTRATEXTUALES}

El grueso de la acción se desarrolla en dos sitios cerrados: el bar y la casa de Anne. Poco y nada se sabe del primero, salvo que se trata de un bar situado en una zona fabril (se oye la sirena que anuncia el final de la jornada laboral), cerca de los muelles (se oye el ruido de una lancha) y frecuentado por obreros. Es el propio narrador quien ofrece esta mínima descripción de un lugar que es mero escenario de una acción cuyo origen se halla en otro lugar y está determinada por otros condicionantes. Por su parte, es por boca de la propia Anne y el propio Chauvin que el lector conoce cómo es la casa de la familia Desbaresdes. Se trata de una propiedad situada frente al mar, en una de las zonas más bonitas de la ciudad. Sin embargo, está rodeada de ligustro y un haya impide ver el mar. Varios indicios llevan a pensar que Anne se siente prisionera -desde la alusión que hace Chauvin al jardín cerrado ("un grand jardin fermé") a la pregunta que le formula: "c'est dans cette maison qu' on vous a épousée il ya maintenant dix ans?"75, pasando por las menciones al haya: "en été, ce hêtre me cache la mer. J'ai

\footnotetext{
${ }^{70}$ Él se acercó a su rostro, bastante cerca, colocó sus manos pegadas a las de ella encima de la mesa. (Duras, ibid, p. 44)

${ }^{71}$ Las manos de Chauvin se acercaron a las de la Anne Desbaresdes. Permanecieorn las cuatro encima de la mesa, alargadas. (Duras, ibid, p. 68)

${ }^{72}$ Él colocó su mano al lado de la de ella, encima de la mesa, en la pantalla de sombra que hacía su cuerpo. (Duras, ibid, p. 88)

${ }^{73}$ Sus manos permanecieron así, rígidas en su posición mortuoria. (Duras, ibid, p. 89)

${ }^{74}$ Sus labios permanecieron los unos sobre los otros, rozándose, a fin de que quedara hecho, y siguiendo el mismo rito mortuorio que sus manos, un instante antes, frías y temblorosas. (Duras, ibid, p. 91)

${ }^{75}$ ¿Allí es donde la casaron hace diez años? (Duras, ibid, p. 35)
} 
demandé qu'un jour on l'enlève de là, qu'on l'abatte"76, "son ombre est comme de l'encre noir"77 o la caracterización del jardín como "parque correctamente cerrado" a cargo del narrador.

El contrapunto a esa haya que le impide ver el mar, símbolo de libertad, son las magnolias presentes en el jardín, cuya importancia narrativa es notoria, como veremos. La primera referencia a esta flor tiene lugar cuando Anne comenta que vive en la última casa del bulevar, justo antes de llegar a las dunas y Chauvin le contesta: "Le magnolia à l'angle gauche de la grille est en fleur"78, prueba inequívoca de que sabe dónde vive su interlocutora. Anne agrega una expansión, la mención a su fuerte aroma: "L'odeur des magnolias est si forte, si vous saviez" 79. Pero ¿no puede ser ésta la respuesta a algo dicho por Anne poco antes? ¿No será la respuesta -no inmediata, pero respuesta al fin- a la mención de su habitación, en el primer piso, a la izquierda, con vistas al mar, por parte de Chauvin? Creemos que sí. Detengámonos ahora un segundo a analizar la combinación de tres elementos mencionados arriba: "grille", "en fleur" y "vous saviez" ${ }^{80}$. Al calor de lo analizado hasta el momento no sería descabellado presumir un mensaje oculto en estas palabras. ¿No podría tratarse de un mensaje "cifrado" que da a entender que Anne es una mujer en la flor de la vida, encerrada tras una reja y que Chauvin lo sabe? Es más, pensamos que todo aboca a una relación parecida -o idéntica- a la de la pareja protagonista del crimen pasional en el bar y con idéntico final, pues las magnolias aportan un nuevo indicio cargado de significado, al elaborar su floración fúnebre ("floraison funèbre") en la noche negra ("nuit noire") de la naciente primavera, en una noche primaveral tardía y fría ("tardive et froide").

Como hemos visto, Chauvin admite saber quién es Anne, dónde vive y que pasea por el Bulevar y reconoce, además, haber rondado su casa. Rebobinando la historia, hemos de decir que Chauvin no sólo ha estado en casa de Anne en ocasión de una recepción organizada por su marido para el personal de la fábrica ("Vous aviez une robe noire très décolletée. Vous nous regardiez avec amabilité et indifférence" ${ }^{\prime 81}$ ), sino que deja entrever haberla rondado:

Souvent, vous regardez ces hommes qui vont à l'arsenal, surtout l'été, et la nuit, lorsque vous dormez mal, le souvenir vous en revient ${ }^{82}$.

Sin embargo, lo que realmente sorprende es que ella admite, aunque sea de forma velada, como es su costumbre, haberlo visto:

\footnotetext{
${ }^{76}$ En verano esa haya me oculta el mar. He pedido que un día me la quiten, que la talen. (Duras, ibid, p. 46)

${ }^{77} \mathrm{Su}$ sombra es como tinta negra. (Duras, ibid, p. 46)

${ }^{78}$ La magnolia, en el ángulo izquierdo de la reja, está en flor. (Duras, ibid, p. 34)

${ }^{79} \mathrm{i} \mathrm{Si}$ supiera! El olor de las magnolias es muy fuerte. (Duras, ibid, p. 35)

${ }^{80}$ Reja. En flor. Usted lo sabía.

${ }^{81}$ Usted llevaba un traje negro muy escotado. Nos miraba con amabilidad e indiferencia. (Duras, ibid, p. 38)

${ }^{82}$ Usted mira con frecuencia a esos hombres que van al arsenal, sobre todo en verano, y, por la noche, cuando duerme mal, vuelve a usted su recuerdo. (Duras, ibid, p. 40)
} 
Lorsque je me réveille assez tôt [...] je les regardent. Et parfois aussi, oui, le souvenir de certains d'entre eux, la nuit, m'est revenu. Je le savais [...] et ... ces dernières années, à quelque heure que ce soit, je le savais toujours, toujours ${ }^{83}$.

Chauvin se arriesga un poco más y va desgranando datos que dan cuenta de esa atención silenciosa que le ha ido prestando. Así, prosigue con la descripción del jardín en una noche de luna y menciona el corredor de la primera planta iluminado, donde se halla la habitación de Anne -"Je vous l'ai dit, parfois je dors mal”"84, se disculpa ella, al tiempo que quita importancia al hecho de que el hombre sepa cuál es su dormitorio $\mathrm{y}$, sobre todo, que la observe desde fuera: "Vous allez aux grilles, puis vous les quittez, puis vous faites le tour de votre maison, puis vous revenez encore aux grilles" ${ }^{85}$. La conversación se torna entonces más íntima. Volviendo sobre aquella soirée para el personal de la fábrica, Chauvin verbaliza un recuerdo:

Au mois de juin de l'année dernière, il y aura un an dans quelques jous [...] Au-dessus de vos seins à moitié nus, il y avait une fleur blanche de magnolia. Je m’appelle Chauvin ${ }^{86}$.

y Anne, contrariamente a su proceder, no sólo contesta abiertamente que lo sabe (“Je le savait"), sino que agrega:

Et aussi que vous êtes parti des Fonderies sans donner de raisons et que vous ne pourrez manquer d'y revenir bientôt, aucune autre maison de cette ville ne pourrait vous employer ${ }^{87}$.

Al cabo de unos minutos, él vuelve a mencionar su habitación e inventa una suposición subida de tono ("Quand les troènes crient, en été, vous fermez votre fenêtre pour ne plus les entendre, vous êtes nue à cause de la chaleur" ${ }^{\prime 8}$ ) y ella se limita a contestar que desea otro vaso de vino.

La noche del segundo viernes hay una recepción en casa de los Desbaresdes, a la que acuden invitados de su mismo círculo social. Anne llega tarde -de hecho, bastante más tarde que sus invitados- y con signos evidentes de estar ebria. Los presentes ya han empezado con el primer plato: un salmón glaseado, de las aguas libres del océano, que continúa su "marcha fatídica" hacia su "total desaparición". Mientras tanto, las cocineras van preparando el segundo plato: pato a la naranja, que es descrito como "pato en su mortaja de naranjas" ("un canard mort dans son linceul d'oranges"). Lentamente comienza la digestión de lo que fuera un salmón, que las invitadas devoran, al tiempo que, en la cocina, la otra víctima espera su turno para

\footnotetext{
${ }^{83}$ Como me despierto tan temprano [...] los veo [a los hombres del arsenal]. Y quizá, sí, el recuerdo de alguno de ellos vuelva a mí por la noche. Lo sabía [...] y estos últimos años, a la hora que fuera, siempre lo sabía. (Duras, ibid, p. 47)

${ }^{84}$ Ya se lo dije, a veces duermo mal. (Duras, ibid, p. 44)

${ }^{85}$ Va hasta la verja, luego la abre, luego le da la vuelta a la casa, luego vuelve otra vez a la verja. (Duras, ibid, p. 52)

${ }^{86}$ En el mes de junio del año pasado, hará un año dentro de unos días [...] Por encima de su pecho semidesnudo, había una flor blanca de magnolia. Me llamo Chauvin. (Duras, ibid, p. 48)

${ }^{87}$ Y también que usted abandonó las Fundiciones sin dar razones y que no tendrá más remedio que volver muy pronto, ya que ninguna otra empresa en esta ciudad podrá darle trabajo. (Duras, ibid, p. 48)

${ }^{88}$ Cuando gritan los ligustros, en verano, usted cierra su ventana para dejar de oírlos, está desnuda debido al calor. (Duras, ibid, p. 50)
} 
ser devorada. Todos interpretan su papel: las mujeres lucen las joyas que sus maridos les han regalado y al beber alzan sus brazos desnudos, "irreprochables", de esposas; todos participan en la conversación partidista y neutra que las normas sociales exigen. Sin embargo, una invitada manifiesta lo siguiente: "Nous sommes toutes pareilles, allez" 89 , comentario que induce a pensar en que hay un cierto paralelismo en la vida de todas ellas.

Esa noche sofocante de primavera en la que las magnolias elaboran su floración fúnebre Chauvin espera frente al jardín de la casa de los Desbaresdes, tal vez con la esperanza de ver a Anne desde la ventama, tal vez con la esperanza de reunirse con ella en el jardín: "Un homme rôde, boulevard de la Mer. Une femme le sait"90, "voici la lune qui se lève sur la mer et sur l'homme allongé" ${ }^{\prime 1}$,

au-delà des stores blancs, la nuit et, dans la nuit, encore, car il a du temps devant lui, un homme seul regarde tantôt la mer, tantôt le parc. Puis la mer, le parc, ses mains ${ }^{92}$,

cet homme a quitté le boulevard de la Mer, il a fait le tour du parc, l'a regardé des dunes, qui, au nord, le bordent, puis il est revenue, il a redescendu le talus, il est redescendu jusqu' à la grève. Et de nouveau il s'y est allongé, à sa place. Il s'étire, reste un moment immobile face à la mer, se retourne sur lui même et regarde une fois de plus les stores blancs devant les baies illuminées. Puis il se relève, prend un galet, vise une de ces baies, se retourne de nouveau, jette le galet dans la mer, s'allonge, s'étire encore et, tout haut, prononce un nom ${ }^{93}$,

[L'homme] prend les grilles dans ses mains, et serre. Comment n'est-ce pas encore arrivé?, l'homme à lâché les grilles du parc. Il regarde ses mains vides et déformées par l'effort, l'homme s'est décidé à repartir vers la fin de la ville, loin de ce parc, l'homme reviendra malgré lui sur ses pas $^{94}$.

Sin embargo, la referencia al "canard mort dans son linceul d'oranges" y al "saumon des eaux libres de l'océan [qui] continue sa marche inéluctable vers sa totale disparition" ${ }^{\prime 95}$ inducen al lector a suponer que esperará en vano. Esa noche de viento sur en la que florecerán las magnolias ("le fleurissement des magnolias sera [...] achevé"),

\footnotetext{
${ }^{89}$ Somos todas iguales, ¿sabe?

${ }^{90}$ Un hombre merodea por el Boulevard de la Mer. Una mujer lo sabe.

${ }^{91}$ La luna se levanta sobre el mar y el hombre tumbado.

${ }^{92}$ Más allá de los visillos blancos, la noche, y, en la noche, todavía, porque dispone de todo su tiempo, un hombre solo mira tan pronto el mar, tan pronto el parque. Luego el mar, el parque, sus manos. (Duras, ibid, p. 79)
}

${ }_{93}^{93}$ Este hombre ha abandonado el boulevard de la Mer, dio la vuelta al parque, lo miró desde las dunas que, al norte, lo rodean, luego regresó, volvió a bajar hasta la playa. Y de nuevo se tumbó, en su lugar. Se estira, permanece un momento inmóvil frente al mar, gira sobre sí mismo y mira una vez más los visillos blancos de los ventanales iluminados. Luego se levanta, toma un guijarro, apunta a uno de esos ventanales, se gira otra vez, arroja el guijarro al mar, se tumba, se estira otra vez y, en voz alta, pronuncia un nombre. (Duras, ibid, p. 79)

${ }^{94} \mathrm{El} \mathrm{hombre} \mathrm{se} \mathrm{ha} \mathrm{incorporado} \mathrm{en} \mathrm{la} \mathrm{playa,} \mathrm{se} \mathrm{ha} \mathrm{acercado} \mathrm{a} \mathrm{la} \mathrm{verja,} \mathrm{los} \mathrm{ventanales} \mathrm{siguen} \mathrm{iluminados,}$ agarra con las dos manos la verja, y aprieta. ¿Cómo es que todavía no ha ocurrido? El hombre ha soltado la verja del parque, mira sus manos vacías y deformadas por el esfuerzo. El hombre ha decidido marcharse hacia el final de la ciudad, lejos del parque. El hombre volverá pese a él mismo sobre sus pasos. (Duras, ibid, p. 82)

${ }^{95}$ El salmón de las aguas libres del océano sigue irremediablemente su camino hacia su total desaparición. (Duras, ibid, p. 75-76) 
el tiempo pasa en vano porque han de florecer para nada ("le temps fuit, égal à luimême, sur ce fleurissement oublié"), mientras la luna se eleva sobre el mar e ilumina a Chauvin, que espera inútilmente, fuera de ese perímetro correctamente cerrado ("correctement clos") que le fuera autorizado a Anne diez años antes ("ce périmètre qui lui fut il y a dix ans autorisé"). Chauvin se aleja del bulevar de la Mer, rodea el parque, observa las dunas que lo bordean al norte, vuelve y pronuncia un nombre, pero las cortinas detrás de las cuales "la otra víctima" espera están cerradas. Por su parte, la magnolia con la que Anne ha adornado su vestido para la recepción se ha marchitado ("Le magnolia entre ses sens se fane tout à fait") y su aroma se desvanece a medida que Chauvin se aleja ("l'odeur des magnolias diminue"). Los invitados se retiran y Anne escapa hacia su habitación ("Anne Desbaresdes "s'éclipsera" “-véase la fortuna del empleo del verbo "s'éclipser"), desde cuya ventana podrá ver que Chauvin se ha ido. De camino, ha pasado por la habitación de su hijo y una sombra ha aparecido en la puerta, oscurecida por la penumbra de la habitación (“Une ombre apparaîtra dans l'encadrement de la porte restée ouverte sur le couloir, obscurcira plus avant la pénombre de la chambre" $\left.{ }^{96}\right)$. Su marido es ya sólo una sombra.

Posiblemente mujeres iguales a las que se han sentado a la mesa de los Desbaresdes la noche del viernes, incluida la propia Anne, mujeres que han recibido la misma educación, que comparten vidas parecidas e idénticos condicionantes hayan vivido en casas como la de la protagonista y sus invitadas; mujeres que quizá han deseado salir de este espacio correctamente acotado en el que su condición social las ha eclaustrado:

Beaucoup de femmes ont déjà vécu dans cette maison qui entendait les troènes, la nuit, à la place de leur cour. Toujours les troènes y ètaient déjà. Elles sont toutes mortes dans leur chambre, derrière ce hêtre qui, contrairiement à ce que vous croyez, ne grandit plus ${ }^{97}$;

mujeres que quizá hayan intentado salir de dicho espacio a través de una relación sin futuro, huyendo hacia delante, hacia la nada y que están bien muertas en vida, bien sin vida, como la mujer asesinada en el bar debajo del piso de Mlle. Giraud: "Toutes ces femmes qui ont vécu derrière ce hêtre et qui sont maintenant mortes".

En síntesis, se puede decir que el espacio se semantiza y los elementos extratextuales devienen significativos, al tiempo que refuerzan la estructura narrativa.

\section{HISTORIAS Y NUDOS NARRATIVOS}

Según Gumperz, la comparación de las estrategias discursivas permite observar cómo los interlocutores son capaces de inferir el mensaje. Y son prescisamente dichas inferencias lo que constituye la base de un discurso coherente. Aunque este autor se ha centrado en la alternancia de códigos y ha estudiado la forma en la que la no

\footnotetext{
${ }^{96}$ Una sombra aparecerá en el marco de la puerta abierta al pasillo y oscurecerá aún más la penumbra del cuarto. (Duras, ibid, p. 84)

${ }^{97}$ Muchas mujeres han vivido ya en esa misma casa y han oído los ligustros, por las noches, en lugar de su corazón. Los ligustros siempre han estado antes allí. Todas han muerto en su habitación detrás de esa haya que, contrariamente a lo que usted cree, ya no crece. (Duras, ibid, p. 49)
} 
comprensión de ciertas claves de contextualización da lugar a una falta de comprensión o a una compresnión errónea, sobre todo en discursos interétnicos, no hay que perder de vista tanto el hecho de que el estudio de las estrategias discursivas permite ver cómo los interlocutores son capaces de negociar el significado e inferir el mensaje superficial o profundo como el que las expresiones empleadas en una conversación -y los elementos proxémicos y no verbales, agregamos nosotros- sólo tienen sentido si ésta tiene lugar en lo que Malinowsky denominaba "contexto de cultura" o "contexto cultural".

Dicho esto, y centrándonos ahora en el conjunto del diálogo que vertebra la narración de Moderato Cantabile, repasemos las pregunas clave que debe contestar todo análisis de la conversación, a saber, ¿qué ocurre?, ¿de qué se habla?, ¿quiénes son los interlocutores?, ¿dónde están? y ¿cómo se dirigen el uno al otro? Como se ha dicho, Anne Desbaresdes y Chauvin entablan un diálogo para dilucidar los motivos por los cuales una mujer ha sido asesinada en el mismo bar que él frecuenta habitualmente y en el que ella ha entrado aparentemente por causalidad. Obviamente, el léxico y los campos semánticos que de él se derivan juegan un papel importante para determinar el tema. Se han analizado también el registro que emplean, los intentos de ella para mantener el decoro y los elementos no verbales que dan cuenta de la relación que han iniciado. Nos centraremos ahora en el segundo de los interrogantes enumerados arriba, es decir, de qué se habla.

Aparentemente hay varios diálogos que se entrecruzan, que surgen y de pronto se agotan, pero que reaparecen al cabo de un tiempo, entremezclados con otros diálogos. Tal es el caso del que gira en torno a la mujer asesinada y, en concreto, cómo puede haber llegado a producirse el fatal desenlace, el que se desagrana en torno al fracaso matrimonial de Mme. Desbaresdes y su vida hastiada o las clases de piano del niño y también el que se desarrolla alrededor de la propia historia entre ambos protagonistas. Sin embargo, creemos que se trata de un solo diálogo, "contaminado" por sub-diálogos que se semiotizan en el verdadero diálogo, en el diálogo profundo, que no es otro que el que se desenvuelve en torno a la propia historia de Chauvin y Anne Desbaresdes. De entre los varios indicios que apoyan esta tesis, se puede mencionar la intervención de la dueña al final del capítulo dos, dedicado al sábado, quien, como una voz en off plantea el verdadero motivo de la aparición de Anne en el bar: “On la voit souvent par la ville [...] avec son petit garçon. À la belle saison tous les jours [...] Le vendredi, une fois par semaine. Hier. Ça lui faisait une sortie, en somme, cette histoire" ${ }^{\prime 98}$ y su contestación a Anne en el capítulo siguiente, que narra lo acontecido el lunes, cuando Anne le pregunta si le extraña volver a verla y la dueña se limita a responder: "Dans mon métier ..."99. Con todo, lo interesante aquí para apoyar la idea que defendemos es no quién narra o quién dice qué, sino quién mira. Así, se lee: “[La dueña] lorgna l' homme à la dérobe -lui aussi avait pâli"100. Poco después,

\footnotetext{
${ }^{98}$ Se la ve a menudo por la ciudad [...], con su hijo. Con buen tiempo, todos los días [...] Los viernes, una vez por semana. Ayer. Esa historia era, a fin de cuenta, para ella, un pretexto para salir. (Duras, ibid, p. 29)

${ }^{99}$ En mi oficio ... (Duras, ibid, p. 32)

${ }^{100}$ Miró de reojo al hombre -él también había palidecido. (Duras, ibid, p. 32)
} 
"les premiers hommes entrèrent au café, s'étonnèrent, interrogèrent la patronne du regard. Celle-ci, d'un léger mouvement d'épaules, signifia qu'elle-même n'y comprenait pas grandchose" $^{\prime 101}$.

Y el segundo viernes, los hombres

"regardèrent encore cette femme, s'étonnèrent encore, mais de loin"102.

Si un nudo narrativo gira alrededor del asesinato en sí y sus protagonistas, otro lo hace en torno al porqué del mismo.

Anne: $\quad$ Et, évidemment on ne peu pas savoir pourquoi? ${ }^{103}$

Chauvin: J'aimerais pouvoir le dire, mas je ne sais rien de sûr ${ }^{104}$.

Anne: $\quad$ Peut-être que personne ne le sait? ${ }^{105}$

Chauvin: Lui le savait. Il est maintenant devenu fou, enfermé depuis hier soir. Elle est morte [...] Ils s'aimaient ${ }^{106}$.

En este momento entra en escena del hijo de Anne Desbaresdes, que le pregunta a su madre si ya sabe por qué ha gritado la mujer, a lo que ella contesta negativamente con un movimiento de cabeza. Chauvin agrega que el asesino trabajaba en el arsenal y que no sabe a qué se dedicaba la mujer. Entonces, Anne lanza una suposición imprevista:

Anne: Peut-être avaient-ils des difficultés, de qu'on appelle des difficultés de coeur alors? ${ }^{107}$

Aquí es la propia dueña la que interrumpe, de nuevo como voz en off, para dar información sobre la mujer asesinada. Dice que estaba casada, que tenía tres hijos y que solía estar ebria. No se produce la respuesta socialmente esperada: un "iqué barbaridad!" o "iqué desgracia”!, sino la aclaración de la dueña de que no le agrada meterse en los asuntos ajenos, comentario éste ambiguo, ya que puede referirse tanto a la mujer asesinada como a Anne y Chauvin. Al alejarse para atender a unos clientes que acaban de entrar, Anne y Chauvin retoman el hilo de la conversación y éste afirma:

Chauvin: Ils devaient avoir des difficultés de coeur, comme vous dites. Mais peut-être n'est-ce pas en raison de ces difficultés-là qu'il l'a tuée, qui sait? ${ }^{108}$

Entonces Anne, al sugerir un posible motivo del asesinato pasional y aportar con ello más información sobre ella misma que sobre la víctima, rebaja el nivel de

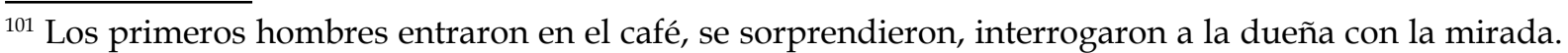
Ésta, con un ligero movimiento de hombros, expresó que ella misma no entendía muy bien de qué iba. (Duras, ibid, p. 39)

${ }^{102}$ Algunos hombres en la barra miraron una vez más a aquella mujer, seguían sorprendidos, pero de lejos. (Duras, ibid, p. 66)

${ }^{103}$ Y por supuesto, no se puede saber por qué. (Duras, ibid, p. 24)

${ }^{104}$ Me gustaría poder decírselo, pero no sé nada seguro. (Duras, ibid, p. 24)

${ }^{105}$ Quizá nadie lo sepa. (Duras, ibid, p. 24)

${ }^{106}$ Él lo sabía. Ahora se ha vuelto loco, le encerraron anoche. Y ella está muerta [...] Se amaban. (Duras, ibid, p. 24)

${ }^{107}$ Puede que tuvieran problemas, lo que se llama problemas del corazón, ¿no? (Duras, ibid, p. 24)

${ }^{108}$ Sí, debían tener problemas del corazón, como usted dice. Y quién sabe si no fue precisamente por culpa de esos problemas por lo que él la mató. (Duras, ibid, p. 25)
} 
protección aconsejable para mantener su reputación ante un extraño con la siguiente intervención:

Anne: Vous croyez qu'il est possible d'en arriver ... là ... autrement que ... par désespoir? ${ }^{109}$

Tenemos, así, un diálogo en el que se barajan hipótesis del porqué del asesinato y que deviene una confesión íntima ante un extraño. Anne Desbaresdes ha roto, pues, la distancia que las normas sociales aconsejan mantener ante una persona de distinto sexo y condición.

La conversación de ambos protagonistas va dejando retazos de información que permiten reconstruir la historia que conduce al asesinato de la mujer. Ante la pregunta de Anne de cómo podrían haber llegado a tal situación, Chauvin esboza una hipótesis:

Ils s'étaient connus par hasard dans un café, peut-être même dans ce café-ci qu'ils fréquentaient tous les deux. Et ils ont commencé à se parler de choses et d'autres ${ }^{110}$.

Minutos más tarde, agrega:

Oui, je crois bien que c'est dans un café qu'ils ont commencé a se parler, à moins que ce soit ailleurs. Ils ont peut-être parlé de la situation politique, de risques de guerre, ou bien d'autre chose $^{111}$.

Más adelante Anne sintetiza:

Alors ils ont parlé, et parlé, beaucoup de temps, beaucoup avant d'y arriver ${ }^{112}$.

Sin embargo, no se limita a repetir las palabras de Chauvin, ya que, por una parte recupera lo dicho por él el viernes a propósito del motivo del asesinato -quizá el hombre la ha matado porque ella se lo ha pedido: "Mais je crois qu'il l'a visée au coeur comme elle lui demandait"113- $y$, por otra, concentra su mensaje en el final de la historia. Y lo hace de forma muy rentable, muy síntetica, a partir del pronombre " $y$ ". Es decir, Anne trae a colación una reflexión anterior y en unas pocas palabras establece un esquema narrativo: la víctima y su asesino iniciaron una relación posiblemente sin futuro y se encontraron en un callejón cuya única salida (el término 'inevitable' se repite a lo largo de la novela) era la muerte de ella, a petición de ella misma.

Cuando los protagonistas se preguntan sobre los motivos que pueden haber llevado a la pareja al trágico fin de su relación, una vez más llama la atención la ambigüedad del diálogo entre Anne y Chauvin, que en ocasiones parece referirse a la pareja que ha protagonizado el incidente del bar o a la relación entre Anne y su marido:

\footnotetext{
${ }^{109}$ ¿Usted cree que es posible llegar ... a eso ... de no ser ... por desesperación? (Duras, ibid, p. 25)

110 Se habían conocido por casualidad en un café, quizás incluso en este café que los dos frecuentaban. Y empezaron a hablarse de una cosa y otra. (Duras, ibid, p. 34)

111 Sí, creo que es en un café donde empezaron a hablarse, a menos que fuera en otro lugar. Tal vez hablaran de la situación política, de los riesgos de la guerra, o de otra cosa. (Duras, ibid, p. 36)

112 Entonces hablaron y hablaron por mucho, mucho tiempo, antes de llegar a eso. (Duras, ibid, p. 37)

${ }^{113}$ Pero creo que le disparó al corazón tal como ella se lo pedía. (Duras, ibid, p. 29)
} 
Peut être par de longs silences qui s'installaient entre eux, la nuit, un peu n'importe quand ensuite, et qu'ils étaient de moins en moins capables de surmonter par rien, rien ${ }^{114}$.

o a la relación con Chauvin:

J'imagine qu'un jour [...] un matin à l'aube, elle a su soudainement ce qu'elle désirait de lui. Tous est devenue clair pour elle au point qu'elle lui a dit quel serait son désir. Il n'y a pas d'explication, je crois, à ce genre de découverte-là ${ }^{115}$.

-sugiere Chauvin, que segundos más tarde agrega:

Vous savez [...] j'imagine aussi qu'il l'aurait fait de lui-même un jour, même sans ses instances à elle. Qu'elle n'était pas seule à avoir découvert ce qu'elle désirait de lui ${ }^{116}$.

Hay múltiples indicios que llevan a la conclusión de que Anne Desbaresdes está insatisfecha con su vida, que ha iniciado una relación extramatrimonial sin futuro, que se encuentra en una encrucijada vital sin salida ("c'est impossible"117). Al cabo de una semana -el segundo viernes, para ser más precisos- Anne vuelve al bar después de la clase de piano de su hijo. Una vez más, el "ruido" presente en la conversación no impide recuperar el verdadero diálogo subyacente. Anne saca a colación las clases de música del niño (“Je me suis mis dans la tête qu'il fallait qu'il sache la musique"118, dice), unas clases que posiblemente haya esgrimido como excusa para acercarse a la zona fabril, donde es posible que esperara encontrar a Chauvin (“J'ai eu l' idée de ces leçons de piano [...] à l'autre bout de la ville, [...] et maintenant je ne peux plus les éviter. Comme c'est difficile"119). Chauvin invade su territorio puesto que no ofrece una respuesta esperada, del tipo: "Sí, la educación musical es importante", o algo por el estilo, sino que menciona la casa de Anne: "Mais je comprends. Alors, ce grand piano, à gauche, en entrant dans le salon?"120. Si se amplía el contexto hasta abarcar más diálogo, se puede incluso presuponer la cualidad proléptica del "Je comprends" de Chauvin cuando se lee a continuación la respuesta de Anne: "Mais il est si petit encore, si petit, si vous saviez, quand on y pense, je me demande si je n'ai pas tort"121. Al volver a casa esa noche, más tarde que de costumbre, pues había sonado la sirena de la fábrica y Anne seguía en el bar, el niño se queja de que están lejos de casa y está

${ }_{114} \mathrm{Tal}$ vez debido a largos silencios que se instalaron entre ellos, por la noche, un poco a todas horas luego, y a que eran siempre menos capaces de superarlo mediante nada, nada. (Duras, ibid, p. 45)

${ }^{115}$ Imagino que un día -dijo-, una mañana al alba, repentinamente, ella supo lo que deseaba de él. Todo se volvió tan claro para ella que le dijo cuál sería su deseo. No hay explicación, creo, para este tipo de descubrimientos. (Duras, ibid, p. 35)

${ }^{116}$ ¿Sabe? -dijo-, imagino también que un día él lo habría hecho por propia iniciativa, incluso sin que ella se lo pidiera. Que ella no fuera la única en descubrir lo que ella deseaba de él. (Duras, ibid, p.36)

${ }^{117}$ Es imposible. (Duras, ibid, p. 92)

${ }^{118}$ Me metí en la cabeza que él tenía que saber música. (Duras, ibid, p. 66)

${ }^{119}$ Tuve la idea de estas clases de piano, le decía, al otro extremo de la ciudad, para ese amor mío, y ahora ya no puedo evitarlas. Qué difícil es. (Duras, ibid, p. 69)

${ }^{120}$ Lo entiendo. Entonces, ¿ese gran piano, a la izquierda, entrando en el salón? (Duras, ibid, p. 66)

${ }^{121}$ Pero es todavía tan pequeño, tan pequeño, ¡si supiera!, pensándolo bien, me pregunto si no me equivoco. (Duras, ibid, p. 66) 
cansado. Su madre lo consuela con un ambiguo "C'est fini, je crois bien"122. ¿En verdad se trata de una pregunta retórica en la que ella se pregunta si tiene la culpa de obligar al niño a tomar clases de piano o se está refiriendo a otro tipo de culpa? La repetición de "si petit" y el uso de pronombre " $y$ " en "on y pense" aluden a otro tipo de culpa -su relación adúltera y la imposiblidad de abandonar a su hijo. En su última cita, Anne le confiesa a Chauvin: “Cet enfant [...] je n'ai pas eu le temps de vous le dire" ${ }^{123}$. ¿Decirle qué? Que no puede abandonar a su hijo, que se ha acabado. Más adelante, la pregunta de Anne acerca de cómo puede haber llegado la mujer asesinada a la conclusión de que la única salida posible era la muerte a manos de su amante: "Elle avait beaucoup $\mathrm{d}^{\prime}$ espoir qu' il y arriverait" 124 (véase nuevamente el uso de “ $\mathrm{y}$ "), se refiere a ella misma y adelanta lo que eventualmente le pedirá a Chauvin. El verdadero diálogo está roto por múltiples interferencias y para su reconstrucción hay que analizarlo en su conjunto, desgranando las locuciones pertenecientes a las profundidades del diálogo, que es donde subyace el tema oculto.

Cabe entonces preguntarse si su affair con Chauvin terminará de la misma manera que la otra pareja. Es posible que sí, ya que existe un nudo narrativo alrededor de la muerte como única salida a su relación y al autor material e intelectual del mismo. Al referirse al asesino de la mujer en el bar, Chauvin ha dicho: "Peut-être a-t-il eu envie de la tuer très vite, dès les premières fois qu'il l'a vue"125 y en otra ocasión, Anne ha especulado: "Elle avait beaucoup d'espoir qu'il y arriverait"126. Aparentemente están hablando de la mujer asesinada y su pareja, pero el verdadero diálogo se refiere a ellos mismos. En su último encuentro, Chauvin dice: “Je n'aurais pas cru que ça arriverait si vite"127, a lo que ella responde de forma oblicua pero llena de significado, como es su costumbre: "A partir de cette semaine, $d$ 'autres que moi mèneront mon enfant à sa leçon de piano chez Mademoiselle Giraud"128. Al final de la novela, Chauvin confiesa: "Je voudrais que vous soyez morte"129 y ella responde: “C'est fait"130.

\section{SEMIÓTICA DE CAPAS}

La semiología, en un intento de apartarse de cualquier modelo preconcebido de análisis textual, aborda el texto per se, es decir, a partir del estudio de los llamados

\footnotetext{
${ }^{122}$ Se acabó, al menos creo. (Duras, ibid, p. 74)

${ }^{123}$ Ese niño [...], no tuve tiempo de decírselo. (Duras, ibid, p. 88)

${ }^{124}$ Quisiera comprender un poco por qué era tan maravilloso su deseo de que él llegara a eso un día. (Duras, ibid, p. 89)

${ }^{125}$ Es posible que haya deseado matarla muy pronto, desde las primeras veces que la vió. (Duras, ibid, p. 90)

${ }^{126}$ Tenía muchas ganas de que esto llegara. . (Duras, ibid, p. 86)

${ }^{127}$ Jamás habría creído que esto llegaría tan pronto. (Duras, ibid, p.86)

${ }^{128}$ A partir de esta semana, otras personas traerán a mi hijo a su clase de piano en casa de la señorita Giraud. (Duras, ibid, p.87)

${ }^{129}$ Desearía que estuviera muerta. (Duras, ibid, p. 92)

${ }^{130}$ Está hecho. (Duras, ibid, p. 92)
} 
elementos sintácticos del relato, que incluyen desde los personajes a las relaciones temporales, pasando por el espacio, la voz del narrador, las visiones, etc. Si entendemos el relato como la forma concreta en que una historia deviene texto y discurso a partir de la voluntad explícita del narrador y si partimos del hecho de que toda historia ha de estar situada necesariamente en el espacio y el tiempo, no es menos cierto que el personaje puede ser considerado el elemento motor de la acción narrativa.

Los distintos modelos elaborados para el estudio de los personajes, desde Propp hasta Souriau, pasando por Bremond, Segre o Greimas, entre otros, son marcos teóricos útiles que, sin embargo, no deben emplearse de forma mecánica. Es decir, no hay que perder de vista el hecho de que son marcos teóricos que posibilitan el análisis de los personajes como elementos sintácticos del relato. Pongamos como ejemplo la teoría de Greimas, que habla de actantes en vez de personajes. Coincide este autor con Propp en considerarlos unidades semánticas sintácticas de la narración, pero a diferencia de él, propone una nomenclatura más abstracta que contempla un sujeto, un objeto, un destinador, un destinatario, un oponente y un ayudante. Este esquema puede ser productivo para el cuento fantástico, pero ello no implica que deba aplicarse de la misma manera en todo tipo de relatos. Es más, no tienen por qué estar todos los actantes presentes. Con todo, creemos que sí es útil para el análisis de los protagonistas de Moderato Cantabile, siempre y cuando se aligere el modelo y se lo reduzca a sólo dos actantes. Por una parte estaría el sujeto o primer protagonista, que es el personaje cuyo deseo de escapar de una vida de hastío motiva la acción y, por otra, el adyuvante, personaje a su servicio que deviene segundo protagonista. Detrás de esta función narrativa se parapetan los dos personajes centrales (Anne Desbaresdes y Chauvin), los dos anónimos con los que se abre el relato (la mujer asesinada en el bar y su asesino) y las demás parejas que se intuyen.

Pero volvamos a la historia. Se han analizado dos historias: la de la mujer asesinada y su asesino y la de Anne Desbaresdes y Chauvin, que creemos son casi idénticas, puesto que se trata de dos mujeres de clase media acomodada, confinadas en un espacio acotado -sus respectivos domicilios y quizá sus respectivos matrimonios-, que inician una relación sentimental con un hombre de clase social inferior, con desenlace fatal para ambas.

Analizado también el diálogo, se observa que es posible reconstruir la historia de la mujer asesinada a partir de lo que en música se denomina "coda", es decir, de la repetición de información anterior, aunque en el caso que nos ocupa hay eventualmente expansiones, es decir, información añadida. Esta historia, de la que se vale Anne para entablar conversación con Chauvin, constituye un marco general en el que se inserta su propia historia, así como la clave que permite establecer un paralelismo entre ambas. Las referencias a la historia base -la del asesinato pasional- suelen estar dadas por yuxtaposición a partir de una repetición y por expansión -Anne le pide una y otra vez a Chauvin que le diga cuál puede ser el motivo del fatal desenlace. Por su parte, la historia de Anne corre paralela a aquella, escondida entre las ambigüedades de un diálogo coherente a partir de los elementos que se han analizado. Y es el análisis de ese diálogo aparentemente no cohesionado pero coherente el que da acceso a las 
claves que permiten desambigüarlo y acceder a la estructura profunda de un relato caracterizado por un argumento al que se llega a partir de -al menos- dos historias similares, con dos actantes y cuatro personajes, un lugar (una pequeña población a orillas del mar), un tiempo -diez días a finales de la primavera -, e idéntico final, aunque podría decirse que el desenlace de la historia de Anne y Chauvin no es explícito, sino que se deja abierto. No hay que olvidar, sin embargo, que es la voluntad del narrador, personaje ficticio situado entre la obra y el lector, quien, valiéndose de los elementos que hemos analizado, a saber, el análisis de la conversación, la proxémica y los elementos no verbales, permite el acceso a las historias contenidas en la obra y su eventual transformación en argumento.

En la animación y en el diseño multimedia, las capas son una especie de transparencias superpuestas, de manera tal que, colocadas unas sobre las otras, la nueva agrega un nuevo elemento visual a las anteriores. Es, pues, notoria su productividad a la hora de organizar el diseño o la narración. En el caso que nos ocupa, creemos que existe una capa base que contiene los principales elementos narrativos, es decir, lugar (un pueblo de la costa, una casa en la zona "bien" del pueblo, el bar), tiempo (primavera) y actantes (una mujer de clase media alta y un obrero fabril), así como una historia base: la relación amorosa entre ambos, relación ésta que termina trágicamente con la muerte de aquella a manos de éste. Las demás historias matizan o concretan los elementos sintácticos del relato. Estas historias, cada una de las cuales podría considerarse una capa, pueden ocultarse o mostrarse según convenga e incluso se puede mostrar sólo aquella parte que interesa dejar expuesta. Por ejemplo, se permite la visualización del actante-sujeto de la acción, léase Anne, la mujer asesinada o la alusión a las otras mujeres que han vivido antes en su casa, pero se oculta el nombre de los demás actantes-adyuvantes a excepción del de Chauvin. Es decir, que se bloquea adrede, tal vez para resaltar sólo su función narrativa, el nombre del asesino y sólo se desbloquea el de Chauvin, quizá por el mismo motivo, ya que es el adyuvante protagonista de la historia central que contiene todas las demás. Chauvin aventura que la mujer asesinada y su asesino pudieron haber empezado a hablar de esto y de lo otro, tal vez de la situación política, de la posibilidad de una guerra o de otra cosa distinta, mientras que él y Anne entablan conversación a partir de la excusa que representa el asesinato pasional en el bar. En síntesis, emergen ligeras diferencias de unas historias cuya estructura narrativa profunda es idéntica.

A esa capa queconstituye una primera estructura narrativa selevan superponiendo tantas otras como posibles historias parecidas hayan podido tener lugar. Para empezar, está la historia que abre el relato: una mujer casada, con tres hijos, y de buena posición social muere a manos de su amante en el bar donde se daban cita. Luego se halla la relación entre Anne Desbaresdes y Chauvin, con notables similitudes -Anne es una mujer casada, con un hijo, de clase acomodada, y Chauvin trabajaba en la fundición. Se han visto indicios del trágico final que le espera. Anne alude a otras mujeres como ella, 
hastiadas, que quizá hayan tenido aventuras similares: "Beaucoup de femmes ont déjà vécu dans cette maison qui entendait les troènes, la nuit, à la place de leur cour"131 y

Un jour, un beau matin, tout à coup, elle rencontrera quelqu'un qu'elle reconnaîtra, elle ne pourra pas faire autrement que de dire bonjour. Ou bien elle entendra chanter un enfant, il fera beau, elle dira il fait beau. Ça recommencera ${ }^{132}$.

La historia de Anne no sólo es la más extensamente narrada -de hecho, es la historia central-, sino que es la que la da pie a reconstruir el argumento base, puesto que a partir de ella se "recuperan" las demás historias. Se podría decir, entonces, que existe una primera capa que tiene los elementos esenciales del relato, una segunda, constituida por la historia que abre el relato, que concreta dichos elementos, y la formada por la historia de Anne, que es la que contiene la máxima información y permite transformar las historias en un único argumento a partir del análisis del diálogo, la proxémica y los elementos no verbales presentes en el mismo.

Aunque el análisis de la conversación y los elementos no verbales han jugado un papel primordial en la reconstrucción del argumento, conviene no olvidar un último elemento, clave para cohesionar el relato: el narrador. Situado desde fuera del relato, se limita a mostrar la parcela de la realidad que él quiere que vea el lector (¿o deberíamos decir el espectador?), mediante el empleo de una técnica muy cinematográfica, típica de la nouvelle vague, con escasez de diálogo, abundancia de planos y silencios, luces y sombras y comentarios del narrador, como si se trata de anotaciones de un guionista de cine. Esto, sumado al hecho de que la acción transcurre en un tiempo acotado, convierte a Moderato Cantabile en una obra moderna e interesante.

\section{BIBLIOGRAFÍA}

André, M. O. (1989): Moderato cantabile, Marguerite Duras -analyse critique, Paris, Hatier. Borgomano, M. (1990): Moderato cantabile - parcour de lectures, Paris Bretrand-Lacoste. Bremond, C. (1973): Logique du récit, París, Seuil.

Duranti, A. (1988): "Ethnography of Speaking: Toward a Linguistics of the Praxis", en Newmyer, F.J. (ed.) Linguistics: The Cambridge Survey, vol. VI. Language: The Socio-Cultural Context, Cambridge, Cambridge University Press, 210-228.

Duras, M. (1993): Moderato Cantabile, Paris, Éditions de Minuit.

Duras, M. (1999): Moderato Cantabile, Madrid, El Mundo.

Fasold R. (1984): The Sociolonguistics of Society, Oxford, Basil Blackwell.

Goodenough, W. (1964): “Cultural Anthropology and Linguistics”, en Hymes, D. (ed.) Language in Culture and Society, Harper and Row, 36-39.

\footnotetext{
${ }^{131}$ Muchas mujeres han vivido ya en esa misma casa y han oído los ligustros por las noches, en lugar de su corazón. (Duras, ibid, p.49)

${ }^{132}$ Un día, una mañana, de pronto, ella encontrará a alguien a quien reconocerá, no podrá hacer de otro modo que saludarle. O también oirá cantar a un niño, hará buen tiempo, dirá hace buen tiempo. Volverá a empezar. (Duras, ibid, p.49)
} 
Goffman, E. (1955): “On Face-work: An Analysis of Ritual Elements of Social Interaction", Psychiatry: Journal for the Study of Interpersonal Processes, 18 (3), 213231.

Goffman, E. (1967): Interaction Ritual: Essays on Face-to-Face Behavior, Anchor Books.

Greimas, A. J. (1971): Semántica estructural, Madrid, Gredos.

Gumperz, J. (1982): Discourse Strategies, Cambridge, Cambridge University Press.

Hymes D. (1974): Foundations in Sociolinguistics, London, Tavistock.

Hymes, D. (1984): "Sociolinguistics: stability and consolidation", International Journal of the Sociology of Language, vol. 45, 773-789.

Hymes, D. (1986): “Discourse. Scope without Depth”, The International Journal of the Sociology of Language", vol. 57: 49-89.

Propp, V. (1974): Morfología del cuento, Madrid, Fundamentos.

Saville-Troike, M. (1989): The Ethnography of Communication, Oxford, Basil Blackwell.

Schegloff, E. (1988): “On an Actual Virtual Servo-Mechanism for Guessing Bad News:

A Single Case Conjecture", Social Problems 35: 442-457.

Hall, E. (1966): The Hidden dimension, New York, Doubleday.

Souriau, E. (1950): Les 200.000 situations dramatiques, Paris, Flammarion. 